\title{
Análise do Coral \\ "Em Memória de Meu Pai" de Camargo Guarnieri
}

\section{Sérgio O. de Vasconcellos Corrêa}

\author{
I - Preâmbulo \\ (Pontêio)
}

O coral "Em memória de meu pai" de Camargo Guarnieri foi composto a 24 de agosto de 1973. Apesar da sua brevidade (38 compassos), configura-se como uma das obras mais significativas e representativas da produção coral do autor. Nela podemos sentir a sua emotividade (contida, é bem verdade, mas...) sempre presente; o extraordinário aprimoramento técnico, responsável pela posição que ocupa no cenário musical das Américas como o compositor mais completo nascido na América Latina, além daquela postura avessa ao exibicionismo, marca patente que tão bem encobre o virtuosismo e faz da sua música (esteticamente nada fácil) um primor de simplicidade.

O texto deste coral denso e conciso tem a sua origem nas duas afirmaçōes contidas no "Livro dos Hebreus" (versículo 13.6) das Sagradas Escrituras, que diz: "O Senhor é o meu ajudador e não temerei o que me possa fazer o homem".

Foi publicado no Álbum "Coro I" editado pela SPMB (Sociedade Pró-Música Brasileira) em 1986, juntamente com obras de José Mauricio Nunes Garcia, Alberto Siciliani, Sílvio Baccarelli, Breno Blauth, Amaral Vieira, Celso Mojola, A. Theodoro Nogueira e S. Vasconcellos Corrèa, os dois últimos representantes da 
"Escola de Composição" do grande mestre paulista nascido em Tietê a 13 de janeiro de 1993 .

\section{II - Salmo \\ (Coral)}

\section{A Relação Texto/Forma}

O Texto: A primeira afirmação ("O Senhor é meu ajudador") apresentada pelas quatro vozes simetricamente dispostas e em forma "silábica", compõe o refrão (A), cuja conclusão se dá na primeira fermata ( $4^{\circ}$ compasso).

Na seqüência encontramos um "episódio" (B) em estilo "fugato", claramente dividido em duas seções, o qual iniciado na "anacruse" do quarto compasso estende-se até o compasso 21. Esse episódio mescla o canto "silábico" e o canto "melismático".

A seção (a) do episódio" (B) dá-se sobre: "E não temerei o que me possa fazer o homem" e é apresentada na seguinte ordem: Soprano, Contralto, Tenor e Baixo.

A segunda (b), decalcada na "afirmação" inicial é exposta inicialmente pelos Contraltos e em seguida pelos Sopranos, Tenores e Baixos.

Após a conclusão do episódio (B) - demarcado por nova fermata (compasso 21) - reaparece o "refrão" (A) imediatamente seguido pela seção (a) do "fugato", agora na ordem: Baixos, Contraltos, Tenores e Sopranos. Segue-se novamente o refrão, agora à guisa de Coda.

ESQUEMA DA ESTRUTURA FORMAL

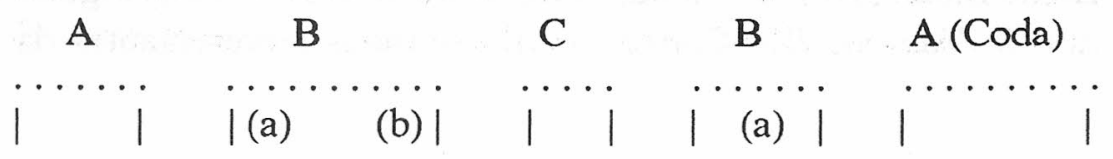




\section{III - Texto/Melodia \\ (Canção)}

\section{A Relação Texto/Melodia}

\section{TEXTO:}

"O Senhor é o meu ajudador e não temerei o que possa fazer o homem".

1.1. Primeira Afirmação: "O Senhor é meu ajudador". o homem".

1.2. Segunda Afirmação: "e não temerei o que me possa fazer

\section{A ESTRUTURAÇÃO MELÓDICA:}

2.1. Primeira Afirmação:

2.1.1. Todas as vozes iniciam a frase na "Dominante" (V) e a concluem na "Final" (III) do modo Frígio.

(Observação) - Com exceção da anacruse inicial, observa-se que a construção melódica do Baixo (Hipo-Frígio) consiste na inversão intervalar (não rigotosa) da linha melódica dos Sopranos (Frígio), enquanto a dos Tenores (Frígio) corresponde à dos Contraltos (Hipo-Frígio).
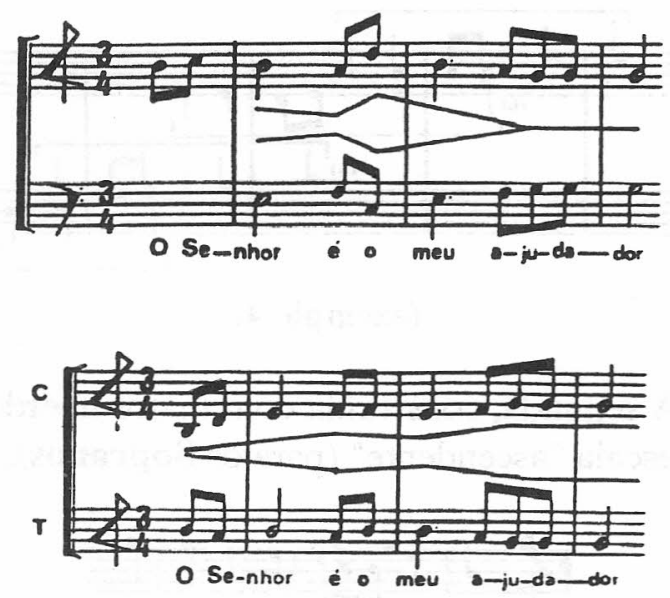

(Exemplos 1 e 2) 
8 Revista Música, São Paulo, v.4, n.1: 5-18 maio 1993

2.1.2. O texto é empregado "silabicamente".

2.1.3. $\mathrm{Na}$ " $2^{\mathrm{a}}$ seção do fugato" o mesmo texto é empregado "melismaticamente".

\subsection{Segunda Afirmação:}

2.2.1. A "segunda afirmação" ( $2^{\mathrm{a}}$ seção) foi dividida em três partes:

a) "e não temerei";

b) "o que me possa fazer";

c) "o homem".

2.2.2. A primeira delas

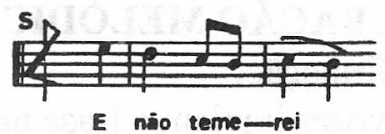

(exemplo 3)

é imitada canonicamente à " 6 a maior" inferior (entre Sopranos e Contraltos); " 5 justa" inferior (entre Contraltos e Tenores) e a " 5 a justa" inferior (entre Tenores e Baixos).

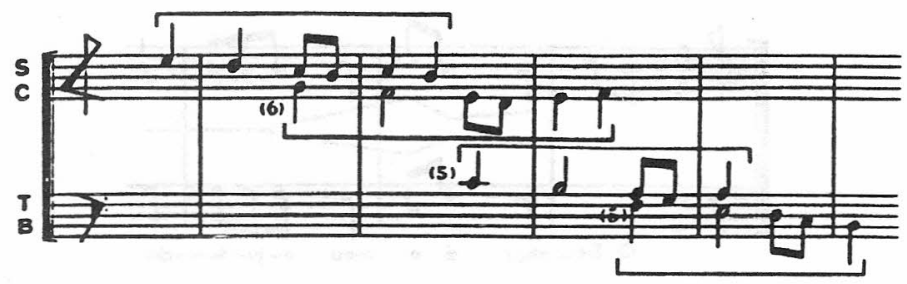

(exemplo 4)

2.2.3. A segunda, construída com maior liberdade, configura-se numa escala "ascendente" (para os Sopranos),

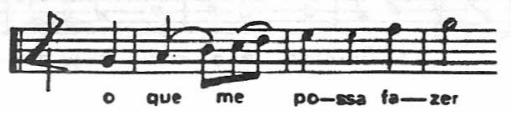

(exemplo 5) 
evoluindo livremente nas demais vozes.

2.2.4. A terceira é caracterizada por uma violenta queda do agudo para o grave (" 8 justa" nos Contraltos e Tenores) emoldurando a palavra "homem",

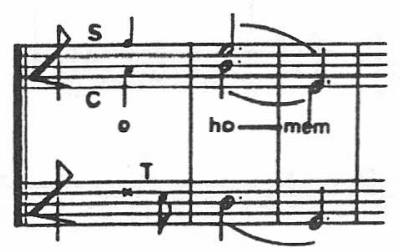

(exemplo 6)

enquanto os Baixos a utilizam naturalmente como conclusão da "resposta" à "proposta" dos Tenores.

2.2.5. $\mathrm{Na}$ " $2^{\mathrm{a}}$ parte do episódio $(\mathrm{B})^{\prime \prime}$ volta o texto da "1 ${ }^{\mathrm{a}}$ afirmação", agora emoldurado por uma linha melódica composta por dois "tetracordes" descendentes apresentados inicialmente pelos Contraltos e a seguir pelos Sopranos ( $6^{\mathrm{a}}$ menor acima), pelos Tenores ( $3^{\mathrm{a}}$ menor composta abaixo dos Sopranos) e pelos Baixos na mesma tessitura dos Tenores, ocasionando um breve e oportuno cruzamento entre essas vozes, dando início a um segundo "fugato".

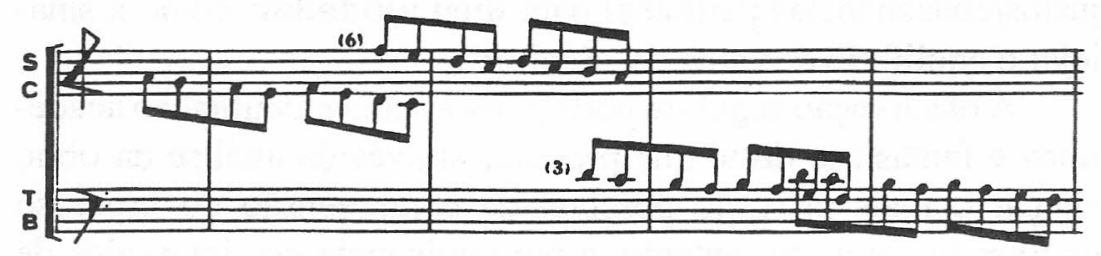

(exemplo 7)

2.2.6. Curiosamente, o contraponto apresentado pelos Sopranos, simultaneamente à terceira entrada do novo "sujeito" (anacruse do compasso 13 , compasso 14 e primeiro tempo do compasso 15) é o mesmo que serviu para caracterizar melodicamente a " $2^{a}$ 
parte" da segunda afirmação: "o que me possa fazer o homem" (compassos 7, 8 e 9).
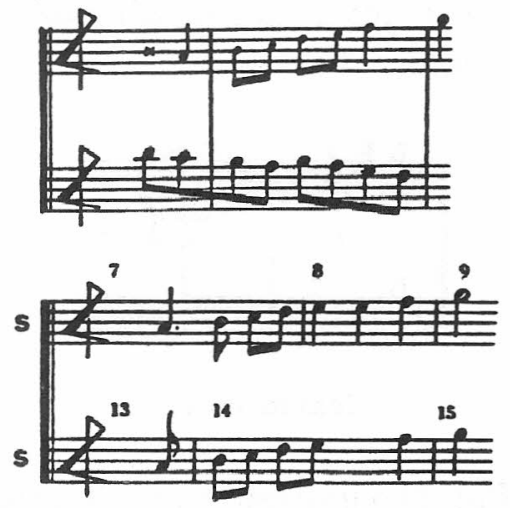

(exemplos 8 e 9)

\section{IV - Texto/Harmonia}

(Toada)

\section{A RELAÇÃO TEXTO/HARMONIA}

É sintomática a utilização do "intervalo" de " $5^{\mathrm{a}}$ justa" na referência ao Senhor e de " $5^{\mathrm{a}}$ justa" e "uníssono" (intervalos justos/consonâncias perfeitas) para meu ajudador, como a sinalejar o equilibrio dos atos do "Senhor".

A observação seguinte pode parecer uma elucubração acadêmica e fantasiosa deste que procura, através da análise da obra, chegar o mais próximo possivel da compreensão do processo criador do autor. No entanto, a predominância dos intervalos de " 4 ", presentes em toda a parte central da mesma (episódio B), por si sóa justificam. Embora o intervalo de " $4^{\mathrm{a}}$ justa" seja considerado (teoricamente) como uma "consonância perfeita", sabemos que os "polifonistas" sempre o consideraram como um intervalo "dissonante" e, como tal, só o admitiam como: "som dissonante" ou "síncopa dissonante"; e nada melhor do que a "dissonância" para 
representar a importância e a angústia sentidas pelo homem em presença do mal, o que o leva, humildemente, a invocar a proteção do Senhor. A própria estrutura polifônica, com a superposição de textos diversos, contribui para reforçar esta sensação de desorientação, responsável pelo ato de invocar a ajuda do Senhor.

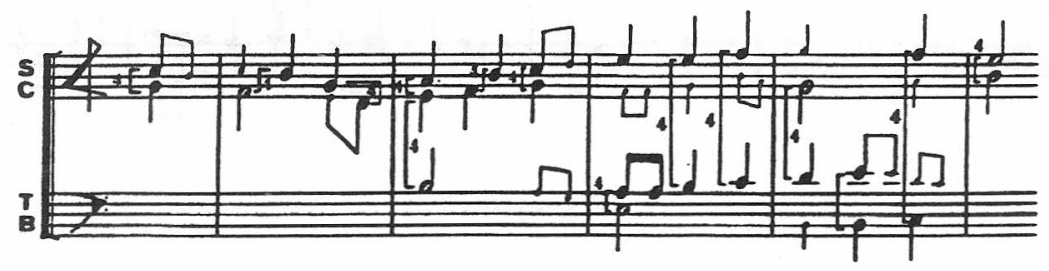

(exemplos das quartas em questão - Ex. 10)

Guarnieri parece apoiar-se nessa primeira premissa e explora abundantemente (na " 1 a parte" do Episódio B) não apenas as seqüências (harmônicas) de " 4 as", como também os acordes formados por " 4 as" sobrepostas.

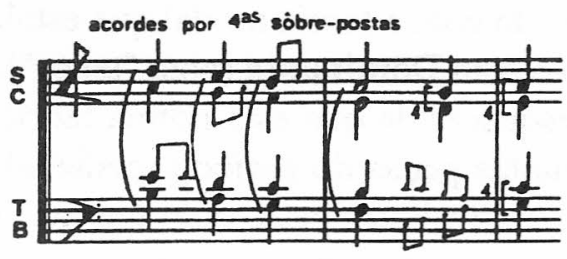

(exemplo 11)

Já ao representar o texto da "1 a afirmação" - "O Senhor é o meu ajudador" - reforça de maneira sutil o efeito de contraste entre o "divino e humano", ao introduzir seqüências de "consonâncias imperfeitas" (" $3^{\text {as }}$ e " e $^{\text {as" }}$ - "Gymel" $/$ "terças caipiras"|"falso bor- 
dão") que aos poucos mesclam-se com as " 4 as", pondo em destaque o contraste entre a perfeição divina e a imperfeição humana.

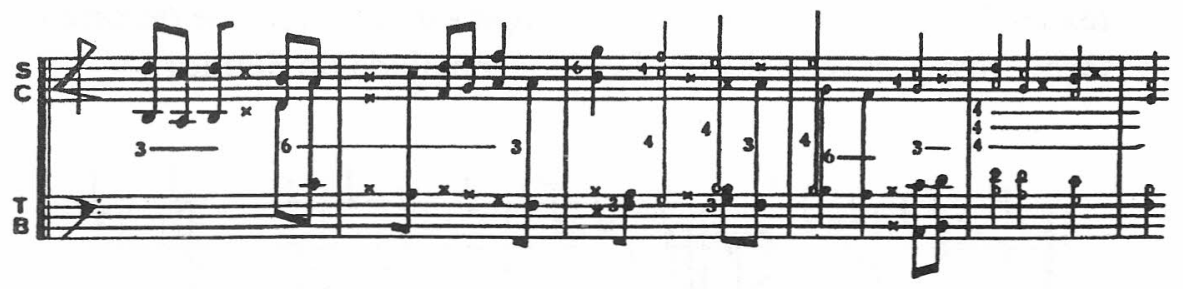

(exemplo 12)

$$
\text { V - (Fugato) }
$$

\section{A ESTRUTURAÇÃO POLIFÔNICA}

$\mathrm{Na}$ estruturação polifônica, Guarnieri usa os modos frígio e hipo-frígio ("Deuterus" autêntico e "plagal") no refrão (seção A) e os modos eólio e hipo-eólio na seção $\mathrm{B}^{(1)}$.

Vejamos: A frase inicial dos Sopranos e dos Tenores está claramente no modo frígio, embora se inicie no $\mathrm{V}$ grau do modo (Si), em desacordo com a teoria modal que estabelece o VI e não - V grau como o som Dominante (nota "tenor"). No entanto, não devemos nos esquecer de que esta norma teórica se fixou lentamente e que muitas peças do período medieval apresentam o $\mathrm{V}$ grau como tal, ou qualquer outro som que na "salmodia" servia como "nota recitativa" e, portanto, "dominava" na Antífona (Dominante).

Observe-se ainda que a conclusão da primeira frase na nota Sol (III grau) vem demonstrar o completo domínio e o conhecimento aprofundado que o compositor tinha da teoria modal, a qual estabelece nítidas diferenças entre o que é uma "nota final" e uma "tônica ou fundamental". A "nota Final" é Sol (III grau), enquanto 
que a "tônica ou fundamentall (I grau), mesmo não estando presente na melodia, é claramente o Mi.
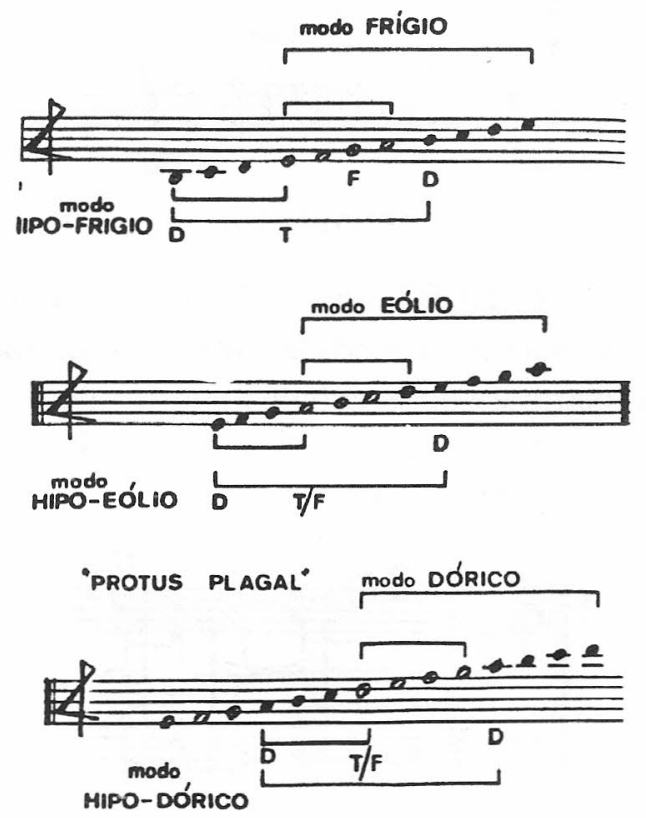

(exemplos 13, 14 e 15)

Os Contraltos e Baixos, por sua vez, partindo do mesmo princípio, iniciam a sua progressão melódica pela Dominante "abaixo" da Tônica, caracterizando dessa maneira o modo "HipoFrígio" ( $4^{\circ}$ modo) ou "Deuterus Plagal", cadenciando para a Tônica e concluindo a frase na "Final" Sol (III grau).

A seção (B) está praticamente no modo Eólio - exceção feita à parte de Contralto (Hipo-Eólio) - cadenciando suspensivamente na Dominante (Mi). A entrada dos Tenores reintroduzindo a " $1^{\mathrm{a}}$ afirmação" é feita também no modo "Hipo-Eólio", predominando a sensação suspensiva, devido à insistência das mesmas vozes sobre a Dominante.

A cadência que encerra esta " 2 a seção", de belíssimo efeito modulante, dá-se com o acorde de Sol Maior sobre a "Final" do modo (Frígio), antecipando a reexposição da "1 ${ }^{a}$ seção". 


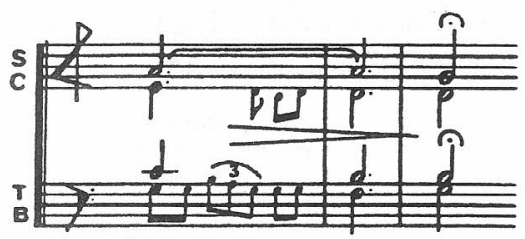

G

(exemplo 16)

A reprise da "seção B" (agora abreviada e com a ordem de apresentação do "sujeito" invertida entre o Soprano e o Baixo) seg te a mesma estrutura apresentada anteriormente, com exceção da seqüência cadencial, agora nitidamente direcionada para a "Tônica" do modo "Frígio" (Mi).

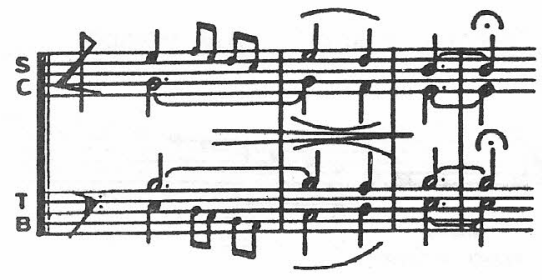

(exemplo 17)

Na conclusão o paralelismo se dá entre as vozes dos Sopranos (modo Frígio) e Tenores (modo Hipo-Frígio) e entre os Contraltos (modo Frígio) e os Baixos (modo hipo-Frígio).
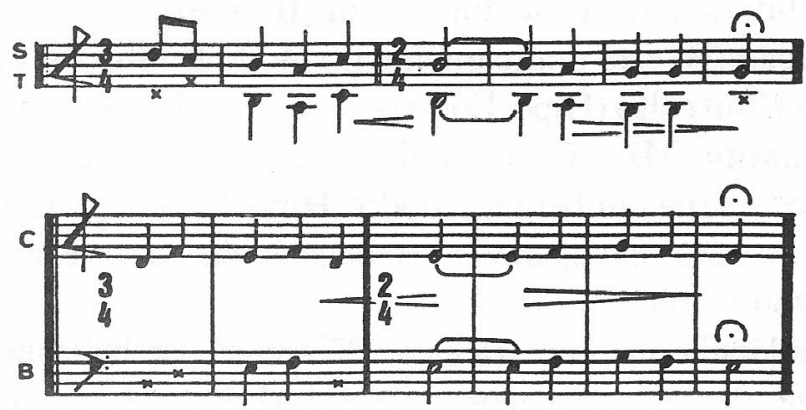

(exemplos 18 e 19) 


\section{BIBLIOGRAFIA}

ALALEONA, Domingos. História da Música. Tradução, ampliação, Capítulos Originais sobre Música Contemporânea e Música no Brasil: Prof. J. C. Caldeira Filho. São Paulo, Ed. Record, s/d.

ANDRADE, Mário de. Pequena História da Música. São Paulo, Livraria Martins Editora, 1944.

BORBA, Tomás \& GRAÇA, Fernando Lopes. Dicionário de Músíca. Lisboa, Ed. Kosmos, 1962.

CORREA, Sérgio Vasconcellos. Introdução à Harmonia. São Paulo, Ricordi Brasileira S.A.E.C., 1975.

SUNOL, Dom Gregório Ma., Rvino, P. Abad, O.S.B. Método Completo de Canto Gregoriano (Según la Escuela de Solesmes). 9a. ed., Monastério de Montserrat, 1952.

\section{NOTAS}

1) Preferimos a nomenclatura adotada por "Albinus Flaccus" (que, no séc. VIII, passou a usar para os modos da Igreja as denominações gregas), pelo fato de que o " $2^{\circ}$ modo" ("Protus plagal"), embora contenha os mesmos sons dos modos "eólio" e "hipo-eólio", difere destes quanto à localização das notas "Tônica" (Final) e "Dominante" (Tenor) na conceituação atual.

Sérgio O. de Vasconcellos Corrêa é Compositor e Professor Adjunto do Departamento de Música do Instituto de Artes da UNESP. 
CAMARGO GUARNIERI, Mozart (Tieté SP - 1/2/1907)

Um dos mais tepresentativus compositores do Brdsil e um dos poucos a conquistar renome internacional, autor de obra volumosa e de qualidade indiscutivel. destaca-se tambem como "o único compositor br asileiro a manter curso do composiç̃o para formar artis. tas conscientes da problemática da música nacional com relaçäo d̀ estutica, às formas, ìngrenapom e aos meios de realizaçzo" (En.

ciclopédis da Músıca Brasıleira erudil s, folciorıca e popular).

\section{VERSICULO}

HEBREUS

13:6

\section{"EM MEMORIA DE MEU PAI"}
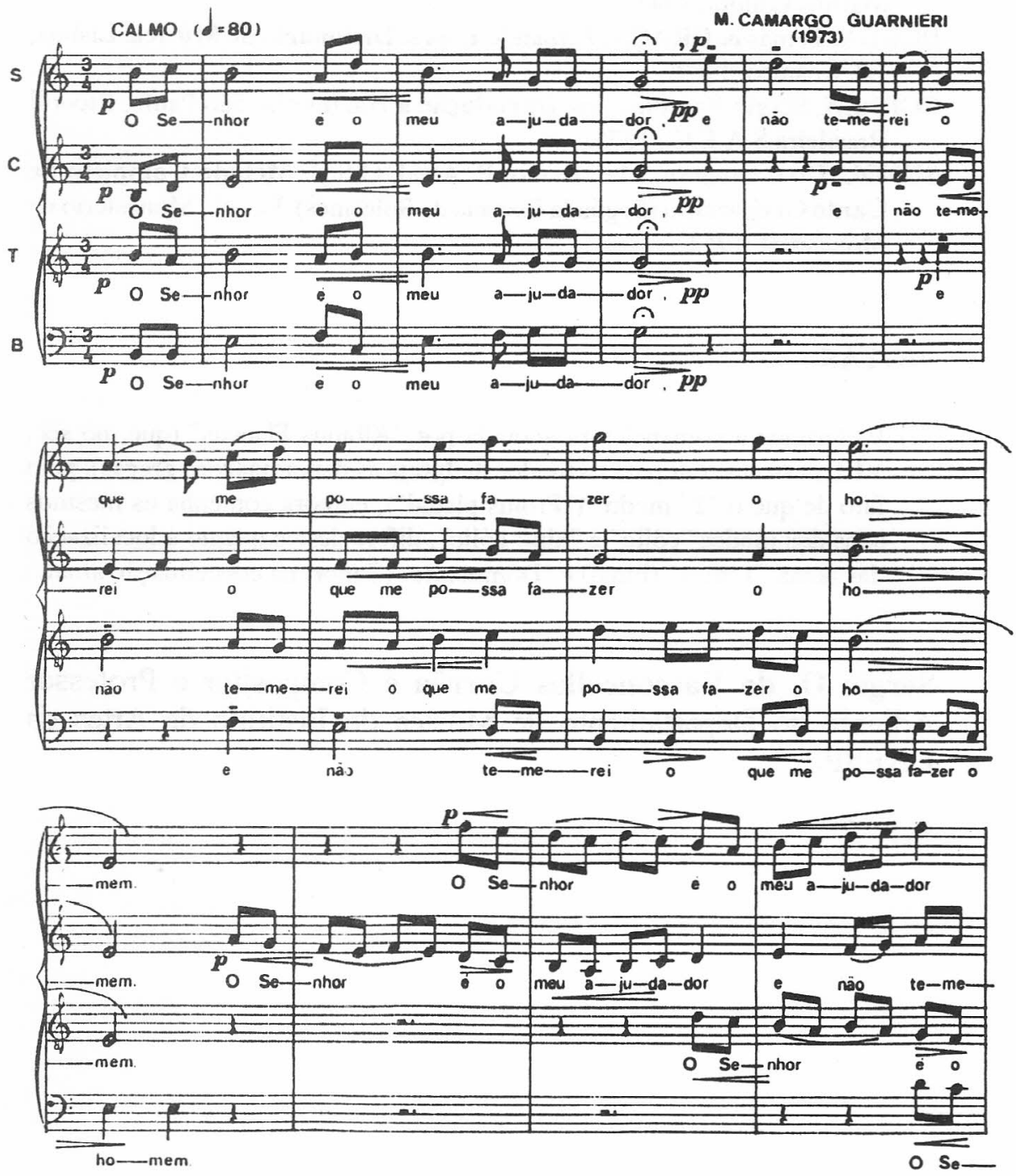

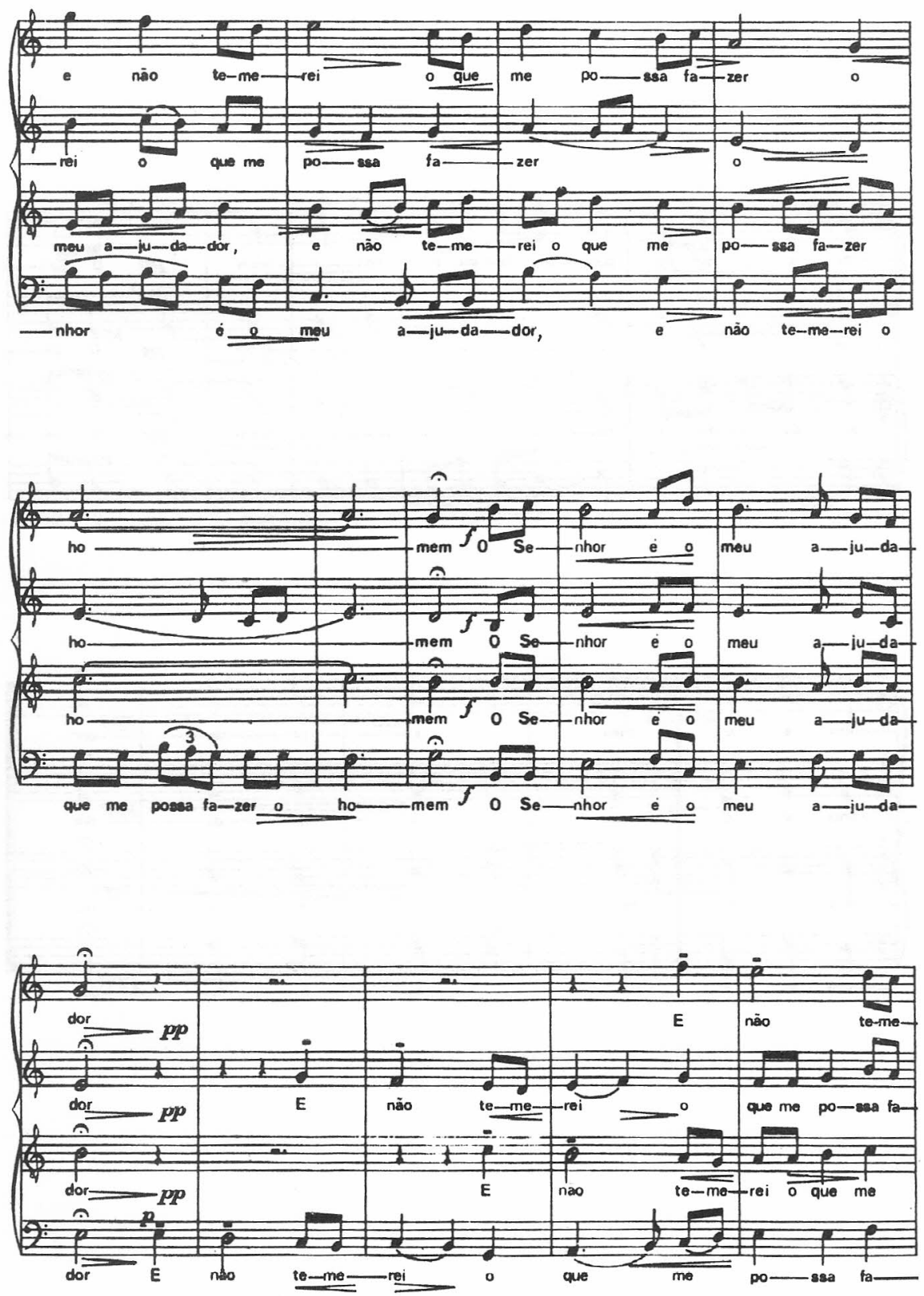

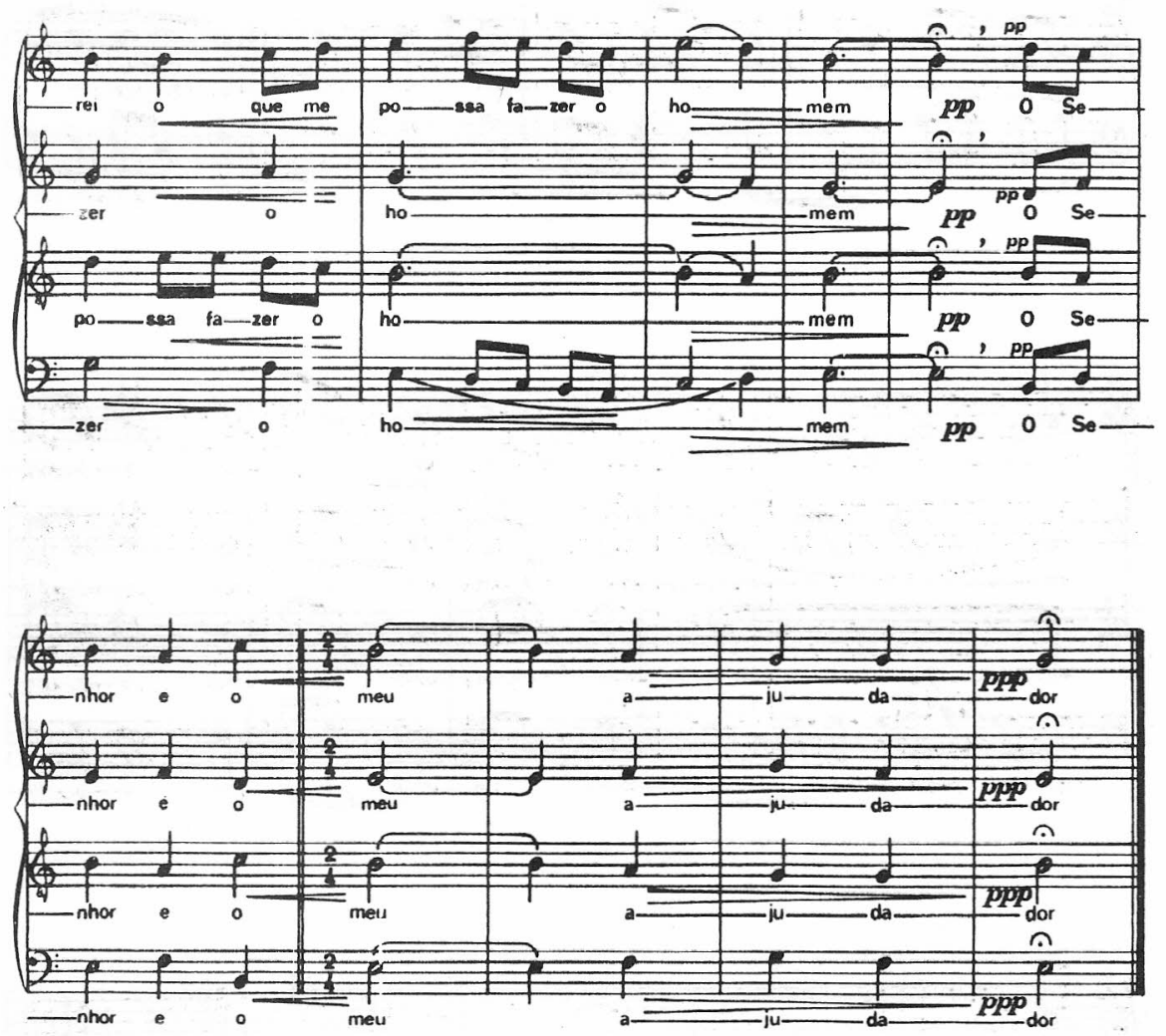